Is the profession progressing in the right direction? Should we be more active in preventative activities, both on an individual basis and nationally? Is there not a need for priority treatment to those patients with acute conditions? Or should we be looking more to be compared with hairdressers and beauticians rather than medical practitioners?

Should I be concerned or am I just an old grump?

M. V. B. Nelson

Lancaster

DOI: 10.1038/sj.bdj.2012.179

\section{ORGANIC TOOTHPASTE}

Sir, a colleague recently drew my attention to an organic, fluoride-free toothpaste that is marketed by The Green People Company Ltd for use by children. The availability of such a product raises a number of issues that dental professionals need to be aware of and prepared to discuss with their patients.

The widespread acceptance of fluoridated toothpastes has resulted in a significant reduction in caries experience since their introduction in the 1970s. ${ }^{1}$

Although fluoride-free toothpastes have retained a niche market, this is growing and the advent of a product specifically aimed at mothers and their children should give the profession cause for concern. The marketing of a child's toothpaste without fluoride in a marketplace where organic products have come to signify improved health benefits is not only misleading, but also potentially harmful.

Whilst the product at $£ 3.50$ per $50 \mathrm{ml}$ is not aimed at children who would be high risk for dental caries on socioeconomic grounds, the use by children who would traditionally be considered low risk has the potential to increase their likelihood of experiencing tooth decay. I'm sure colleagues are familiar with the child whose parents have taken to making healthy fruit smoothies only to find that this has resulted in tooth surface loss or dental caries; parents' best intentions frequently have unintended consequences.

Considering the continued presence of 'low' fluoride (<1000 ppm) children's toothpastes it is vital that all dental professionals enquire as to the type of toothpaste used by their younger patients. Furthermore, appropriate advice based upon the latest Department of Health and BASCD guidance ${ }^{2}$ should always be provided. The approach to parents who have opted for fluoride-free toothpastes for their children should aim to outline the benefits of fluoride, whilst remaining sensitive to any lifestyle choices they may subscribe to.

In summary, dental care professionals should be mindful of the presence of this unnecessary product and discourage its use by their paediatric patients.

A. McKay Sheffield

1. Marinho V C, Higgins J $P$, Logan $S$, Sheiham A. Fluoride toothpastes for preventing dental caries in children and adolescents. Cochrane Database Syst Rev 2003; CD002278.

2. Department of Health and British Association for the Study of Community Dentistry. Delivering better oral health: an evidence-based toolkit for prevention. 2nd ed. London: DoH/BACSD, 2009.

DOI: $10.1038 /$ sj.bdj.2012.180

\section{A CONTRARY VIEW}

Sir, I am a general anaesthetist with a specialist interest in paediatric anaesthesia. I have recently presented a lecture to the British Dental Association North West Hospitals Group meeting on sedation and anaesthesia in children. My subsequent discussion with dental colleagues was illuminating. It would seem that a potentially unintended consequence of Poswillo and subsequent recommendations in the late 1990s by the General Dental Council and the Royal College of Anaesthetists is a received wisdom amongst dentists that general anaesthesia for dental procedures is an option of last resort, and that sedation is, where possible, always the preferred option.

My own opinion on this issue, with which the majority of anaesthetists I feel sure agree, would indicate a contrary view. The prospect of a heavily sedated patient, whose airway is difficult to monitor and shared with a dentist, is the worst option of all. The less subjective end point of general anaesthesia as compared with sedation, along with an airway that is secure and full monitoring including capnography established prior to treatment com- mencing, all contribute to a less stressful experience for all involved: dentist, anaesthetist and, most importantly, the patient.

The relative safety of sedation versus general anaesthesia, as recently published NICE guidelines indicate, is difficult to quantify as sedation practice in the UK has not been properly audited. Extensive data do exist demonstrating the (extremely small) risk associated with general anaesthesia in otherwise healthy individuals. No such data exist in the UK with respect to sedation. One of the NICE recommendations is that this situation needs to be addressed. Data from the USA compiled by the US Paediatric Research Consortium reveal that even in specialist centres, adverse airway events can occur in as many as 1:200 sedation cases. This may be as high as 1:60 when propofol sedation is used.

The potential undesirable result of the current mindset of dentists is that many patients, on whom it would be easier, less psychologically damaging and potentially safer to operate under general anaesthesia in a hospital setting, are not offered this option, or are actively discouraged due to perceived increase in risk. This also may lead in some cases to 'healthcare professionals' (the language of NICE) providing sedation that is of necessity at the 'heavy' end of the spectrum, without the skills and ongoing experience to deal with unforeseen consequences. The NICE guidelines are sufficiently open to interpretation that well-intentioned but misguided individuals may offer sedation that is neither to the benefit of the patient, and in the worst case scenario, potentially less safe than the option of general anaesthesia.

\section{A. P. Dobson} Manchester

Useful resources:

1. National Institute for Health and Clinical Excellence (NICE). Sedation in children and young people (CG112). December 2010. Available at: http://guidance.nice.org.uk/CG112

2. The Independent Expert Group on Training Standards for Sedation in Dentistry (IEGTSSD). A guide to maintaining professional standards in dentistry. September 2011. Available at: http:/I www.saad.org.uk/system/files/documents/ CPD\%20Document\%20Text\%20Cropped.pdf

DOI: $10.1038 /$ sj.bdj.2012.181 